УДК 550.846:[546.98+581.6]

ИЗУЧЕНИЕ СОДЕРЖАНИЯ ПАЛЛАДИЯ

B SCUTELLARIA BAICALENSIS GEORGI, LAMIACEAE

\author{
${ }^{1}$ Пшеничкина Ю.А., ${ }^{2}$ Пшеничкин А.Я. \\ ${ }^{\prime}$ ФГБУН «Центральный сибирский ботанический сад СО РАН», Новосибирск, \\ e-mail: scutel@yandex.ru; \\ ${ }^{2}$ ФГАОУ ВО «Национальный исследовательский Томский политехнический университет», \\ томск, e-mail:paya@tрu.ru
}

\begin{abstract}
В работе приводятся результаты изучения накопления и распределения палладия в разных частях лекарственного растения Scutellaria baicalensis Georgi, сем. Lamiaceae (шлемник байкальский). Исследовались корни, стебли, листья, цветки, семена, а также почва. Определение палладия проводили инверсионно вольтамперометричесим методом. Пробы отбирались из естественных мест произрастания растения (Юго-Западное Приморье, Амурская, Читинская области) и интродуцированного в Центральном сибирском ботаническом саду СО РАН (г. Новосибирск). Было установлено, что палладий определяется как в почвах, так и в разных частях S. baicalensis во всех исследованных местообитаниях. В местах произрастания S. baicalensis coдержание палладия в почве изменяется от 0,27 до 7,0 г/т. Содержание палладия в разных частях растения колеблется в широких пределах от 0,065 до 6,0 г/т. Не установлено четкой закономерности в концентрации палладия между надземной и подземной частями растения. Для растений из Амурской обл. характерно концентрирование палладия в корнях. Для остальных мест произрастания характерно либо близкое соотношение палладия в корнях и надземной части, либо палладий накапливается, в основном, в надземной части растений. Коэффициент биологического поглощения (КБП) палладия для S. baicalensis из разных мест произрастания изменяется от 0,07 до 4,45. Значения КБП палладия, превышающие единицу, отмечены нами для растений из Читинской обл., для отдельных частей растений из Амурской обл. и Юго-Западного Приморья. В остальных местах произрастания КБП приближается или гораздо меньше единицы. Полученные данные могут быть использованы в фитотерапии и при биогеохимических методах поиска месторождений полезных ископаемых.
\end{abstract}

Ключевые слова: палладий, накопление, Scutellaria baicalensis, Lamiaceae, лекарственное растение

\title{
THE STUDY OF THE CONTENT OF PALLADIUM IN SCUTELLARIA BAICALENSIS GEORGI, LAMIACEAE
}

${ }^{1}$ Pshenichkina Yu.A., ${ }^{2}$ Pshenichkin A.Ya.

${ }^{1}$ Central Siberian Botanical Garden SB RAS, Novosibirsk, e-mail: scutel@yandex.ru;

${ }^{2}$ National Research Tomsk Polytechnic University, Tomsk, e-mail: paya@tpu.ru

This paper presents the study of accumulation and distribution of palladium in different parts of a medicinal plant Scutellaria baicalensis Georgi, Lamiaceae (Baikal skullcap). The roots, stems, leaves, flowers, seeds, and soil were studied. The palladium content was detected using stripping voltammetry. The samples were collected from natural habitats of S. baicalensis (south-western Primorye, Amur and Chita regions) and in Central Siberian Botanical Garden of SB RAS (Novosibirsk) where the plant was introduced. Palladium was detected both in the soil and in different parts of the plant in all the studied habitats. In the habitats of S. baicalensis, the content of palladium in the soil varied from 0,27 to $7,0 \mathrm{~g} / \mathrm{t}$. The content of palladium in different parts of the plant varied over a wide range from 0,065 to $6,0 \mathrm{~g} / \mathrm{t}$. No regularity was found in the distribution of palladium in the underground and overground parts of the S. baicalensis. Accumulation of palladium in roots was characteristic for the plants growing in Amur region. In other regions, either relatively equal content of palladium in roots and shoots was detected, or palladium accumulated mostly in the overground part of the plants. Biological absorption coefficient (BAC) of palladium for S. baicalensis in different habitats varied from 0,07 to 4,45 . BAC values of palladium higher than 1 were noted for the plants from Chita region and for different parts of the plants from Amur region and south-western Primorye. In other habitats, BAC tended to 1 or was significantly lower than 1 . The obtained data can be used in herbal therapy and in biogeochemical search of mineral deposits.

Keywords: palladium, accumulation, Scutellaria baicalensis, Lamiaceae, medicinal plant

Концентрация химических элементов в растениях может характеризовать несколько существенных аспектов. На этом основан биогеохимический метод поиска месторождений полезных ископаемых [1]. Предполагается, что уровни содержания элементов в растениях отражают колебания концентраций их в породах около корневой системы растений. Полученные данные также могут быть отражением био- геохимической ситуации экологически неблагополучных регионов [2]. Концентрация химических элементов в лекарственных растениях может превышать допустимые уровни ПДК для пищевых растений и БАД. При использовании растительного сырья в фитотерапиии или как продукта питания микроэлементный состав может существенно влиять на свойства сырья, а значит, на состояние живых организмов. 
Цель исследования - оценка содержания и особенностей поглощения палладия лекарственным растением Scutellaria baicalensis Georgi, Lamiaceae (шлемник байкальский) из разных мест естественного произрастания и при интродукции.

Палладий используется в автомобильной промышленности, стоматологии и ювелирном деле. Проводятся исследования по созданию биоактивных препаратов палладия, обладающих противоопухолевой активностью [3]. Причем соединения палладия в экспериментах на животных показывают более высокую активность и более низкую токсичность, чем соединения платины. Геохимический барьер палладия механический. Некоторые соединения токсичны [4].

Содержание палладия в некоторых растениях $\left[6^{+} ; 7^{*} ; 8 * *\right]$

\begin{tabular}{|c|c|c|}
\hline Вид & $\begin{array}{c}\text { Часть } \\
\text { растения }\end{array}$ & $\begin{array}{l}\text { Палла- } \\
\text { дий, г/т }\end{array}$ \\
\hline $\begin{array}{l}\text { Abies sp.* } \\
\text { Пихта }\end{array}$ & $\begin{array}{c}\text { ветви, } \\
\text { кора }\end{array}$ & $\begin{array}{c}0,005- \\
0,010\end{array}$ \\
\hline $\begin{array}{l}\text { Alnus crispa }{ }^{+} \\
\text {Ольха кудрявая }\end{array}$ & $\begin{array}{l}\text { ветви } \\
\text { листья }\end{array}$ & $\begin{array}{l}0,044 \\
0,042 \\
\end{array}$ \\
\hline $\begin{array}{l}\text { Arctostaphilus nummularia** } \\
\text { Толокнянка монетчатая }\end{array}$ & побеги & 0,011 \\
\hline $\begin{array}{l}\text { Betula papirifera }^{+} \\
\text {Береза бумажная }\end{array}$ & $\begin{array}{l}\text { ветви } \\
\text { листья }\end{array}$ & $\begin{array}{l}0,27 \\
0,16\end{array}$ \\
\hline $\begin{array}{l}\text { Eucalyptus sp. }{ }^{* *} \\
\text { Эвкалипт }\end{array}$ & листья & 0,0035 \\
\hline $\begin{array}{l}\text { Lactuca virosa ** } \\
\text { Латук компасный }\end{array}$ & листья & 0,005 \\
\hline $\begin{array}{l}\text { Quercus chrysolepsis ** } \\
\text { Дуб золоточешуйчатый }\end{array}$ & побеги & 0,040 \\
\hline $\begin{array}{l}\text { Quercus lobata ** } \\
\text { Дуб лопастной }\end{array}$ & побеги & 0,011 \\
\hline $\begin{array}{l}\text { Picea mariana }{ }^{+} \\
\text {Ель черная }\end{array}$ & $\begin{array}{c}\text { ветви } \\
\text { Хвоя } \\
\end{array}$ & $\begin{array}{c}0,016 \\
0,16\end{array}$ \\
\hline $\begin{array}{l}\text { Picea pungens ** } \\
\text { Ель колючая }\end{array}$ & побеги & 0,003 \\
\hline $\begin{array}{l}\text { Pinus sp.* } \\
\text { Сосна }\end{array}$ & $\begin{array}{c}\text { ветви, } \\
\text { кора }\end{array}$ & $\begin{array}{c}0,005- \\
0,010\end{array}$ \\
\hline $\begin{array}{l}\text { Pinus banksiana }{ }^{+} \\
\text {Сосна Банкса }\end{array}$ & $\begin{array}{c}\text { древеси- } \\
\text { на }\end{array}$ & 0,0052 \\
\hline $\begin{array}{l}\text { Pinus radiata } * * \\
\text { Сосна лучистая }\end{array}$ & побеги & 0,0015 \\
\hline $\begin{array}{l}\text { Pinus resinosa } * * \\
\text { Сосна смолистая, красная }\end{array}$ & побеги & 0,011 \\
\hline $\begin{array}{l}\text { Populus fremontia ** } \\
\text { Тополь Фремонта }\end{array}$ & листья & 0,004 \\
\hline $\begin{array}{l}\text { Prunus domestica ** } \\
\text { Слива домашняя }\end{array}$ & побеги & 0,005 \\
\hline $\begin{array}{l}\text { Traogopogon porrifolias ** } \\
\text { Козлобородник пореелистный }\end{array}$ & листья & 0,008 \\
\hline
\end{tabular}

Из всех металлов платиновой группы палладий обладает наибольшей биодоступностью, подвижен в окружающей среде и способен достаточно интенсивно поглощаться живыми организмами, в том числе и растениями [5]. Уровни накопления палладия в различных растениях колеблются в широких пределах (табл. 1).

Ранее нами в $S$. baicalensis было определено 26 элементов: $\mathrm{Ag}, \mathrm{As}, \mathrm{Au}, \mathrm{Ba}, \mathrm{Br}$, $\mathrm{Ca}, \mathrm{Ce}, \mathrm{Co}, \mathrm{Cr}, \mathrm{Cs}, \mathrm{Eu}, \mathrm{Fe}, \mathrm{Hf}, \mathrm{Hg}, \mathrm{La}, \mathrm{Lu}$, $\mathrm{Na}, \mathrm{Ni}, \mathrm{Rb}, \mathrm{Sb}, \mathrm{Sc}, \mathrm{Se}, \mathrm{Sm}, \mathrm{Th}, \mathrm{U}, \mathrm{Zn}[9 ; 10]$. Было установлено, что для естественных мест произрастания характерно накопление элементов в $S$. baicalensis в основном в корнях, для интродуцентов - чаще всего в листьях. Возможно, это связано с тем, что при интродукции происходит ускорение процессов в онтогенезе растений и физиолого-биохимические реакции организмов могут быть несколько иными, чем в естественных местообитаниях.

\section{Материалы и методы исследования}

S. baicalensis распространен в Восточном Забайкалье, Среднем Приамурье, Юго-Западном Приморье, а также в Монголии, Китае, Даурии, Маньчжурии, Японии. Растение содержит широкий спектр веществ, основными действующими веществами считаются флавоноиды, в частности - байкалин [11]. S. baicalensis рекомендован при лечении гипертонии I, II стадии, а также как вспомогательное средство при лечении онкологических заболеваний. Растение может также использоваться как декоративное.

Материал для исследований содержания палладия отбирался нами из естественных мест произрастания S. baicalensis: Приморский край (пп. Чернятино, Пограничный, Комиссарово), Амурская обл. (д. Семеновка, гг. Свободный, Благовещенск), Читинская обл. (г. Борзя, с. Карымская, пп. В. Ключи, Бишигино, Матусово, Ключевское, Тасуркай, Октябрьское), а также интродуцированного в Центральном сибирском ботаническом саду СО РАН, г. Новосибирск (ЦСБС). Пробы растительного материала и почвы брались в фенологические фазы цветения и созревания семян.

Определение палладия проводили в «Инновационном научно-образовательном центре «Золото - платина» при Томском политехническом университете инверсионно вольтамперометричесим методом [12]. Химик-аналитик 3.С. Михайлова. 


\section{Результаты исследования} и их обсуждение

Палладий определяется в почвах во всех исследованных местах произрастания S. baicalensis. Наибольшие содержания палладия отмечены в почвах Юго-Западного Приморья - 3,8-7,0 г/т. Содержание палладия в почвах Амурской обл. составило 0,7-1,3 г/т. В других местах произрастания S. baicalensis содержания палладия в почвах близки (0,27-0,51 г/т).

Палладий в S. baicalensis нами определен впервые. Установлено, что элемент содержится в различных частях растения в разных соотношениях (рисунок). В корнях S. baicalensis накапливаются повышенные концентрации палладия, и они нередко выше, чем в почве. Так, в растениях из Амурской обл. содержание палладия в корнях в 1,5-2 раза выше, чем в почвах, а корнях из пп. Тасуркай, В. Ключи, Карымская Читинской обл. в 2-3 раза выше, чем в почвах.

Наибольшие содержания палладия в корнях S. baicalensis из Пограничного - 2,9 г/т (Юго-Западное Приморье) и Амурской обл. (1,21-2,1 г/т). Близкие значения палладия в корнях растения из Чернятино $(0,71$ г/т), Комиссарово (0,61 г/т), Тасуркай $(0,7$ г/т), В. Ключи $(0,71$ г/т), Карымская $(0,85$ г/т). Наименьшие содержания отмечены в корнях S. baicalensis из Матусово $(0,11$ г/т), Ключевское $(0,12$ г/т) и ЦСБС $(0,26$ г/т). Было также установлено, что содержание палладия в корнях S. baicalensis увеличивается с возрастом растений. Так, содержание палладия в корнях растений в возрасте 1-2 лет при интродукции в ЦСБС составляет в среднем 0,29 г/т, 5-7 лет $-0,43$ г/т.

Самое высокое содержание палладия в стеблях $S$. baicalensis из Чернятино $(6,0$ г/т) и Пограничного $(5,0$ г/т). В остальных местах произрастания $S$. baicalensis содержание палладия составляет 0,54-1,2 г/т, кроме Семеновки, где отмечаются самые низкие содержания палладия в стеблях растений 0,065 г/т. Концентрация палладия в стеблях интродуцированных растений в условиях ЦСБС составляет в среднем 0,354 г/т. Содержание палладия в стеблях S. baicalensis из Юго-Западного Приморья может превышать содержание элемента в корнях в 5-6 раз. В большинстве мест произрастания растений из Читинской обл. и ЦСБС содержание палладия также выше в стеблях, чем в корнях. Растения из Амурской обл. накапливают палладий в основном в корнях.

Концентрация палладия в листьях S. baicalensis из разных мест произрастания изменяется в широком диапазоне. Наибольшая концентрация палладия отмечена в листьях S. baicalensis из Пограничного $(2,3$ г/т), при наименьшем значении в растениях из Семеновки (0,085 г/т). Содержание палладия в листьях S. baicalensis, интродуцированного в ЦСБС, не высокие $(0,087-0,30$ г/т).

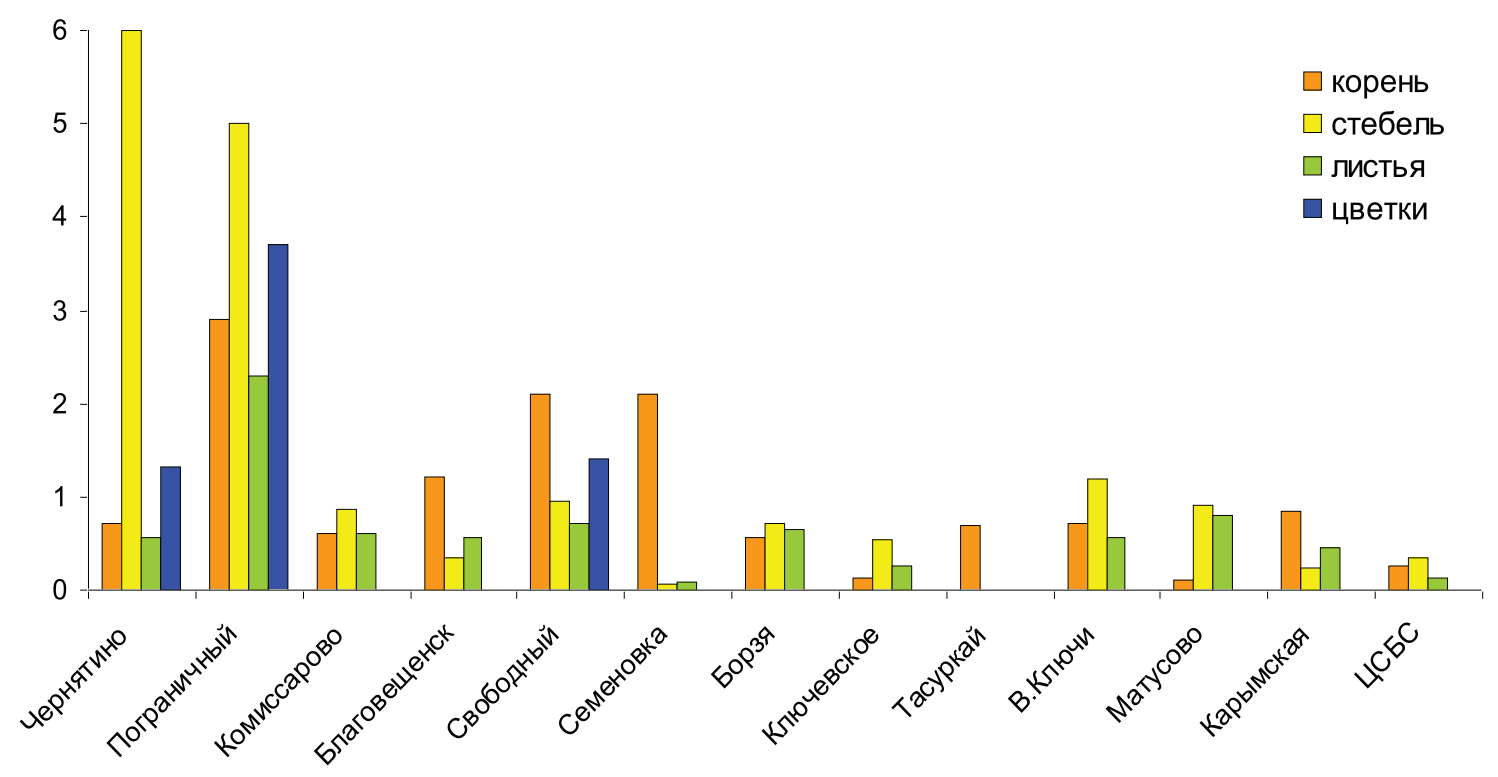

Содержание палладия (2/m) в Scutellaria baicalensis из разных мест произрастания 
Таблица 2

Коэффициент биологического поглощения палладия для Scutellaria baicalensis разных мест произрастания

\begin{tabular}{|c|c|c|c|c|c|}
\hline \multirow[t]{2}{*}{ Место сбора } & \multicolumn{5}{|c|}{ Коэффициент биологического поглощения } \\
\hline & корень & стебель & листья & цветки & семена \\
\hline \multicolumn{6}{|c|}{ Юго-Западное Приморье } \\
\hline Чернятино & 0,19 & 1,6 & 0,15 & 0,35 & $-^{*}$ \\
\hline Пограничный & 0,47 & 0,81 & 0,37 & 0,60 & - \\
\hline Комиссарово & 0,09 & 0,12 & 0,09 & - & - \\
\hline \multicolumn{6}{|c|}{ Амурская область } \\
\hline Благовещенск & 1,59 & 0,46 & 0,75 & - & - \\
\hline Свободный & 1,83 & 0,83 & 0,63 & 1,22 & - \\
\hline Семеновка & 1,62 & 0,05 & 0,07 & - & 0,50 \\
\hline \multicolumn{6}{|c|}{ Читинская область } \\
\hline Борзя & 0,72 & 0,92 & 0,85 & - & - \\
\hline Ключевское & 0,34 & 1,54 & 0,77 & - & - \\
\hline Тасуркай & 3,36 & - & - & - & - \\
\hline В. Ключи & 2,63 & 4,45 & 2,07 & - & - \\
\hline Матусово & 0,22 & 1,78 & 1,59 & - & - \\
\hline Карымская & 2,02 & 0,57 & 1,07 & - & - \\
\hline \multicolumn{6}{|c|}{ Новосибирская область } \\
\hline ЦСБС & 0,97 & 1,21 & 0,83 & 0,44 & 0,41 \\
\hline
\end{tabular}

П р и м е ч а и е . * - прочерк означает отсутствие данных.

В цветках S. baicalensis из трех исследованных местообитаний отмечается высокое содержание элемента: Пограничный $-3,7$ г/т, Чернятино - 1,32 г/т, Свободный $-1,4$ г/т. Интересно отметить, что содержание палладия в цветках растений почти в 2 раза выше, чем в листьях. В двух исследованных местообитаниях содержание палладия в семенах растений ниже по сравнению с цветками: Семеновка $-0,65$ г/т, ЦСБС $-0,18$ г/т.

Необходимо отметить, что нами не было выявлено четкой закономерности в концентрации элемента между надземной и подземной частями растений. В Амурской обл. палладия накапливается в корнях больше по сравнению с надземной частью (Благовещенск и Свободный - больше чем в 2 раза, Семеновка - в 7,8 раза, Карымская в 2,4 раза). Для остальных естественных мест произрастания и интродукции характерно либо близкое соотношение палладия в корнях и надземной части (Приморье: Пограничный, Комиссарово; Читинская обл.: Борзя, В. Ключи; ЦСБС), либо палладий накапливается в основном в надземной части (Приморье: Чернятино - в 3,7 раза; Читинская обл.: Ключевское - в 3,4 раза, Матусово - в 7,8 раза). Возможно, это связано с возрастом исследованных растений или антиконцентрационными барьерами.
Для характеристики интенсивности поглощения элемента растением используют коэффициент биологического поглощения (КБП) - отношение содержания элемента в растении к содержанию элемента в горной породе или почве, на которой произрастает растение [13]. КБП палладия для S. baicalensis изменяется в широких пределах от 0,07 до 4,45 (табл. 2).

Самые высокие показатели КБП, превышающие единицу, для всех частей растений отмечены нами для растений из В. Ключей и для корней из Тасуркай (Читинская обл.). КБП для корней растений из Амурской обл., стеблей растений Чернятино (Юго-Западное Приморье), Ключевское, Матусово (Читинская обл.), листьев Матусово приближается к 2. То есть в этих местообитаниях происходит накопление элемента растением. В других местах произрастания S. baicalensis КБП приближается или меньше единицы.

\section{Заключение}

Таким образом, в результате наших исследований было установлено, что палладий обнаруживается как в почвах, так и в различных частях Scutellaria baicalensis Georgi, Lamiaceae (шлемник байкальский) во всех исследованных местообитаниях (Юго-Западное Приморье, Амурская, Читинская обл. и интродуцированного в ЦСБС, г. Но- 
восибирск). Содержание палладия в почвах установлено в пределах 0,27-7,0 г/т, в различных частях растения - 0,065-6,0 г/т. Нами не было выявлено явной закономерности в концентрации палладия в растении между его надземной и подземной частями. Для растений из Амурской обл. характерно концентрирование палладия в корнях. Для остальных мест произрастания характерно либо близкое соотношение палладия в корнях и надземной части, либо палладий накапливается в основном в надземной части. КБП палладия для S. baicalensis изменяется в широких пределах 0,07-4,45. КБП, превышающие единицу, отмечены нами для растений из Читинской обл. и для отдельных частей растений из Амурской обл. и ЮгоЗападного Приморья. В остальных местообитаниях КБП приближается или гораздо меньше единицы. Полученные данные могут быть использованы при биогеохимических методах поиска месторождений полезных ископаемых и в фитотерапии.

Работа выполнена в рамках государ ственного задания Центрального сибирского ботанического сада СО РАН № AAAA-A17-117012610053-9.

При подготовке публикации использовались материаль биоресурсной научной коллекизии ЦСБС СО РАН «Коллекциии живых растений в открытом и закрытом грунme», УHУ № USU 440534.

\section{Список литературы}

1. Ворошилов В.Г. Геохимические методы поисков месторождений полезных ископаемых. - Томск: Изд-во Томского политехнического университета, 2011. - 104 с.

2. Коломиец Н.Э., Калинкина Г.И., Марьин А.А., Бондарчук Р.А. Экологические аспекты заготовки и использования лекарственного растительного сырья // Изв. Самар. науч центра Рос. акад. наук. - 2010. - Т. 12, № 1 (8). - С. 2051-2054.

3. Чертко Н.К., Чертко Э.Н. Геохимия и экология химических элементов: Справочное пособие. - Минск: Издательский центр БГУ, 2008. - 140 с.

4. Улахович Н.А., Медянцева Э.П., Бабкина С.С. и др. Металлы в живых организмах. - Казань: Казанский университет, 2012. - 102 c.

5. Янин Е.П. Платиновые металлы в окружающей среде (распространенность, источники, техногенное загрязнение, рециклинг) // Научные и технические аспекты охраны окружающей среды. - 2008. - № 5. - С. 2-94.

6. Ковалевский А.Л., Ковалевская О.М., Прокопчук С.И. Микробиолиты элементов платиновой группы в золе растений, определяемых сцинтилляционным эмиссионным спектральным анализом // Отечественная геология. 2004. - № 4. - C. 39-45.

7. Dunn C.E. Biogeochemistry as an aid to exploration for gold, platinum and palladium in the Northern forests of Saskatchewan, Canada // J. Geochem. Explor. - 1986. - Vol. 25. № 1. - P. 21-40.

8. Kothny E.L. Palladium in plant ash. // Plant and Soil. 1979. - Vol. 53. Iss. 4. - P. 547-550.

9. Банаева Ю.А., Пшеничкин А.Я. Элементный состав Scutellaria baikalensis Georgi// Сибирский экологический журнал. - 1999. - № 3. - С. 271-275.
10. Пшеничкина Ю.А., Пшеничкин А.Я. Некоторые закономерности накопления золота в шлемнике байкальском // Успехи современного естествознания. - 2016. - № 10. C. $152-156$.

11. Артемов И.А., Бадритдинов Р.А., Байков К.С. и др. Иллюстрированная энциклопедия растительного мира Сибири. - Новосибирск: Арта, 2009. - 392 с.

12. Kolpakova N.A., Oskina Y.A., Djyachenko E.N., Pshenichkin A.Y. Determination of platinum metals in carbonaceous mineral raw materials by stripping voltammetry // Procedia Chemistry. - 2015. - Vol. 15. - P. 335-341.

13. Ганжара Н.Ф., Борисов Б.А., Ефимов О.Е., Злобина М.В. Ландшафтоведение. - М.: Изд-во РГАУ-МСХА, 2016. $-130 \mathrm{c}$.

\section{References}

1. Voroshilov V.G. Geokhimicheskie metody poiskov mestorozhdenii poleznykh iskopaemykh [Geochemical methods of mineral deposits exploration]. Tomsk, Iz-vo Tomskogo politekhnicheskogo universiteta, 2011, 104.

2. Kolomiets N.E. Kalinkina G.I. Mar'in A.A. Bondarchuk R.A. Ecological aspects of preparation and use of medicinal vegetative raw materials [Ekologicheskie aspekty zagotovki $\mathrm{i}$ ispol'zovaniia lekarstvennogo rastitel'nogo syr'ia ]. Izv. Samar. nauch. tsentra Ros. akad. nauk - Proceedings of the Samara scientific center, Russian Academy of Sciences, 2010, vol. 1, no. 12, pp. 2051-2054.

3. Chertko N.K. Chertko E.N. Geokhimiia i ekologiia khimicheskikh elementov: Spravochnoe posobie [Geochemistry and ecology of the chemical elements: a reference guide]. Minsk, Izdatel'skii tsentr BGU, 2008, 140.

4. Ulakhovich N.A Mediantseva E.P. Babkina S.S. i dr. Metally v zhivykh organizmakh [Metals in living organisms]. Kazan', Kazanskii universitet, 2012, 102.

5. Ianin E.P. Platinum metals in the environment (prevalence, sources, man-made pollution, recycling) [Platinovye metally $\mathrm{V}$ okruzhaiushchei srede (rasprostranennost', istochniki, tekhnogennoe zagriaznenie, retsikling)]. Nauchnye i tekhnicheskie aspekty okhrany okruzhaiushchei sredy - Scientific and technical aspects of environmental protection, 2008, no. 5, pp. 2-94.

6. Kovalevskii A.L. Kovalevskaia O.M. Prokopchuk S.I. Microbiotites of platinum group elements in plant ash determined by the scintillation emission spectral analysis [Mikrobiolity elementov platinovoi gruppy v zole rastenii, opredeliaemykh stsintilliatsionnym emissionnym spektral'nym analizom]. Otechestvennaia geologiia - Russian Geology, 2004, no. 4, pp. 39-45.

7. Dunn C.E. Biogeochemistry as an aid to exploration for gold, platinum and palladium in the Northern forests of Saskatchewan, Canada. J. Geochem. Explor., 1986, vol. 1, no. 25, pp. $21-40$.

8. Kothny E.L. Palladium in plant ash. Plant and Soil, 1979, vol. 4, no. 53, pp. 547-550.

9. Banaeva Iu.A. Pshenichkin A.Ia. Elemental composition of Scutellaria baicalensis Georgi [Elementnyi sostav Scutellaria baikalensis Georgi]. Sibirskii ekologicheskii zhurnal - Contemporary Problems of Ecology, 1999, no. 3, pp. 271-275.

10. Pshenichkina Iu.A. Pshenichkin A.Ia. Some regularities of accumulation of gold in Scutellaria baicalensis [Nekotorye zakonomernosti nakopleniia zolota $\mathrm{v}$ shlemnike baikal'skom]. Uspekhi sovremennogo estestvoznaniia - Progress of modern natural Sciences, 2016, no. 10, pp. 251-256.

11. Artemov I.A. Badritdinov R.A. Baikov K.S. i dr. Illiustrirovannaia entsiklopediia rastitel'nogo mira Sibiri [The illustrated encyclopedia of the plant world of Siberia]. Novosibirsk, Arta, 2009, 392.

12. Kolpakova N.A. Oskina Y.A. Djyachenko E.N. Pshenichkin A.Y. Determination of platinum metals in carbonaceous mineral raw materials by stripping voltammetry. Procedia Chemistry, 2015, no. 15, pp. 335-341.

13. Ganzhara N.F. Borisov B.A. Efimov O.E. Zlobina M.V. Landshaftovedenie [Landscape science]. Moscow, Izd-vo RGAU-MSKhA, 2016, 130. 